\title{
$\alpha$-Lipoic Acid Promotes Neurological Recovery After Ischemic Stroke by Activating the Nrf2/HO-1 Pathway to Attenuate Oxidative Damage
}

\author{
Chengmei Lv Surendra Maharjan Qingqing Wang Yongxin Sun Xu Han \\ Shan Wang Zhengchun Mao Yanming Xin Bing Zhang \\ Department of Anesthesiology, Second Affiliated Hospital of Harbin Medical University, Harbin, China
}

\author{
Key Words \\ $\alpha$-Lipoic acid $\bullet$ Stroke $・ N r f 2 \cdot$ Heme oxygenase-1
}

\begin{abstract}
Background/Aims: Alpha-lipoic acid ( $\alpha$-LA) has been demonstrated to be protective against cerebral ischemia injury. Herein, we investigate the neuroprotective effect and underlying mechanisms of $\alpha$-LA. Methods: In vivo study, $\alpha$-LA was administered intravenously upon reperfusion of transient middle cerebral artery occlusion. Garcia score was used to evaluate neurologic recovery. Infarct volume was examined by TTC staining, and oxidative damage was evaluated by ELISA assay. In an in vitro study, neurons were pretreated with $\alpha$-LA at different doses and then subjected to OGD. Lentiviral vectors were applied to knockdown nuclear factorerythroid 2-related factor-2 (Nrf2) or heme oxygenase-1 (HO-1). Cell viability was measured using CCK8. Protein expression was evaluated using western blot, and immunofluorescence staining was assessed. Results: $\alpha$-LA significantly reduced the infarct volume, brain edema, and oxidative damage and promoted neurologic recovery in rats. Pretreatment of $\alpha$-LA caused an obvious increase in cell viability and a decrease in intracellular reactive oxygen species. Western blot analyses and immunofluorescence staining demonstrated a distinct increase in $\mathrm{Nrf2}$ and HO-1 protein expression. Conversely, knockdown of Nrf2 or HO-1 resulted in the down-regulation of HO-1 protein and inhibited the neuroprotective effect of $\alpha$-LA. Conclusion: $\alpha$-LA treatment is neuroprotective and promotes functional recovery after ischemic stroke by attenuating oxidative damage, which is partially mediated by the $\mathrm{Nrf2} / \mathrm{HO}-1$ pathway.
\end{abstract}

\section{Introduction}

(C) 2017 The Author(s) Published by S. Karger AG, Basel

Stroke is the second leading cause of death worldwide [1] . Ischemic stroke caused by either a sudden reduction or complete blockage of cerebral blood flow accounts for $85 \%$ 
of all stroke cases [2]. Tissue plasminogen activator is the only drug approved by the Food and Drugs Administration to treat acute ischemic stroke [3]. However, because of its narrow therapeutic window $(4.5 \mathrm{~h})$, no more than $5 \%$ of patients benefit from it [3]. Thus, effective and neuroprotective agents are urgently required.

Cerebral ischemia/reperfusion (I/R) injury involves complex pathophysiologic mechanisms, such as the release of excitatory neurotransmitters, elevation of intracellular $\mathrm{Ca}^{2+}$ levels, inflammation, oxidative stress and apoptosis [4]. Oxidative stress, which plays a vital role in the pathogenesis of cerebral I/R injury [5,6], is caused by an imbalance between the production of ROS and its effective removal by endogenous scavenger enzymes and protective antioxidants [7]. Oxidative modification of intracellular molecules, such as proteins, lipids, and DNA, by ROS leads to neuronal injury and necrosis $[8,9]$.

Alpha-lipoic acid (LA, chemical name: 1, 2-dithiolane-3-pentanoic acid) is a thiol antioxidant that is considered to be a fundamental complement of $\alpha$-keto acid dehydrogenase complexes of the mitochondria and to play a significant role in metabolism [10]. Previous studies about the regulation of lipoic acid on ischemic stroke have been reported in animal models $[11,12]$ and in clinical study [13]. The cellular and molecular mechanisms associated with the protective effects of LA in ischemic stroke are partially be attributed to downregulation of microglial activation [11] and activation of insulin receptor [12]. In addition, LA attenuates cardiomyoctyes necrosis and apoptosis by activating the PI3K/Akt pathway as well as subsequent Nrf2 and HO-1 in experimental animal models of myocardial ischemia [14].

However, whether LA protects the brain from oxidative stress through the Nrf2/HO-1 pathway has not been clearly clarified and more solid evidences are needed. In this study, we evaluated the protective effects of $\alpha$-LA using in vivo and in vitro ischemic paradigms and investigated the possible role of $\mathrm{Nrf} 2 / \mathrm{HO}-1$ in LA protection against stroke.

\section{Materials and Methods}

\section{Animals}

All animal procedures were performed in adherence with the National Institutes of Health Guidelines on the Use of Laboratory Animals and were approved by the Harbin Medical University Ethics Committee on Animal Care. Adult male Sprague-Dawley rats weighing 220-250 g were housed under a controlledtemperature $\left(23^{\circ} \mathrm{C}\right)$ environment under a 12 -h light/dark cycle and provided with free access to water and food. All studies involving animals are reported in accordance with the ARRIVE guidelines for reporting experiments involving animals $[15,16]$.

\section{Transient middle cerebral artery occlusion (MCAO)}

The rats were anesthetized with sevoflurane (5\% for induction and 3\% for maintenance). The temperatures were maintained at $37.0 \pm 0.5^{\circ} \mathrm{C}$ with a warming pad. MCAO was carried out by the intraluminal suture technique as described previously [17] with slight modifications. Briefly, a ventral midline neck incision was made to expose and isolate the left common carotid arteries, internal carotid arteries, and external carotid arteries. The external carotid arteries were ligated, and the internal carotid arteries were clipped temporarily. A silicon rubber-coated monofilament (tip diameter $0.37 \pm 0.02 \mathrm{~mm}$, Doccol Corporation) was inserted into the internal carotid arteries via the external carotid arteries. Laser Doppler flowmetry (TF5000; PERIMED AB; Stockholm; Sweden) was used to verify the occlusion over the skull located $4 \mathrm{~mm}$ lateral and $1.5 \mathrm{~mm}$ posterior to bregma [18]. A decrease of cerebral blood flow to $30 \%$ of baseline indicated successful occlusion. After $2 \mathrm{~h}$ occlusion, reperfusion was performed by withdrawing the filament. Sham-operated rats received identical surgeries except for the filament insertion.

\section{Animal groups}

In the pre-experiment, the animals were randomly divided into six groups on the basis of whether they received a sham operation or MCAO operation and whether they received saline or $\alpha$-LA at a range of doses, which were administered immediately after reperfusion through the left external jugular vein in 


\section{Cellular Physiology Cell Physiol Biochem 2017;43:1273-1287 \begin{tabular}{l|l} 
DOI: 10.1159/000481840 & $\begin{array}{l}\text { O 2017 The Author(s). Published by S. Karger AG, Basel } \\
\text { www.karger.com/cpb }\end{array}$
\end{tabular}}

Lv et al.: $\alpha$-LA Activates Nrf2/HO-1 Pathway After Stroke

equivalent volumes: (1) Sham group, (2) Control group, (MCAO + saline) (3) LA10 group, (MCAO + 10 mg / kg $\alpha$-LA (Sigma, St. Louis, MO)). (4) LA20 group, (MCAO + $20 \mathrm{mg} / \mathrm{kg} \alpha$-LA). (5) LA40 group, (MCAO + 40 $\mathrm{mg} / \mathrm{kg} \alpha$-LA). (6) LA80 group, (MCAO + $80 \mathrm{mg} / \mathrm{kg} \alpha$-LA). The results shown that there was no significant difference in TTC staining, brain edema and neurological outcomes between the LA10 group and the Control group, and no statistical differences were observed between the LA40 group and LA80 group. Based on these results, the LA20 group and LA40 group were selected for further study.

\section{Behavioral testing}

The 18-point Garcia score was used to evaluate the sensor motor function [19] at $24 \mathrm{~h}$ post reperfusion by observers who were blinded to the experimental groups. The Garcia score was based on the following tests: symmetry of limbs (0-3 points); spontaneous activity ( $0-3$ points); forepaw outstretching (0-3 points); climbing (1-3 points); body proprioception (1-3 points); response to vibrissae touch (1-3 points).

\section{Infarct volume assessment and brain water content}

TTC staining was used to evaluate the infarct volume at $24 \mathrm{~h}$ after MCAO by investigators who were blinded to the experimental groups. The brains were cut into six 2-mm-thick slices and incubated in PBS containing $1 \%$ TTC at $37^{\circ} \mathrm{C}$ for $10 \mathrm{~min}$ [20]. The slices were photographed subsequently and infarct sizes were analyzed using digital image analysis software (Image J) by investigators who were blinded to the experimental groups. The infarct volume was presented as follow to control for unwanted sources of variation: [infarct area - (ipsilateral area - contralateral area)] / contralateral area $\times 100 \%$ [21]. Brain edema was calculated as [(ipsilateral area - contralateral area) / contralateral area] $\times 100 \%$ [20].

\section{Assessment of oxidative stress}

The left cerebral penumbra tissue was collected as previously described [22] at $24 \mathrm{~h}$ after reperfusion and stored at $-80^{\circ} \mathrm{C}$. The brain tissues were homogenized in phosphate buffer (pH 7.4) and centrifuged at 10, $000 \mathrm{~g}$ at $4^{\circ} \mathrm{C}$ for $10 \mathrm{~min}$. The supernatants were collected and used to access the activity of SOD, GSH-Px and MDA with commercially available ELISA kits (Nanjing Jiancheng Bioengineering Institute, Nanjing, China). The reagents, samples, and working standards were prepared according to the manufacturer's instructions at room temperature. Each sample was run in duplicate and evaluated using a microplate reader (BioTek Instruments Inc, Winooski, VT), as recommended by the manufacturer.

\section{Western blot analysis of $\mathrm{Nrf2}$ and $\mathrm{HO}-1$}

The brain tissue samples of the ipsilateral penumbra and primary cortical neurons were lysed with RIPA buffer (Beyotime, Jiangsu, China). Subsequently, the homogenates were centrifuged at 13, $200 \mathrm{~g}$ for $15 \mathrm{~min}$ at $4^{\circ} \mathrm{C}$ (Eppendorf, Hamburg, Germany), and the supernatants were collected for whole cell protein extraction or nuclear protein extraction as previous described [23] with slight modification. The protein concentrations were determined by BCA protein assay (Beyotime, Jiangsu, China). Protein samples were then subjected to SDS polyacrylamide gel electrophoresis. The gels were transferred onto $0.45 \mu \mathrm{m}$ polyvinylidene difluoride membranes (Millipore Corporation, Bedford, MA) and blocked with 5\% skim milk powder in Tris Buffered Saline with Tween. Then, the membranes were probed with primary antibodies against HO-1 (1:1000, Proteintech, Chicago, IL), Nrf2 (1:1000, Abcam, Cambridge, Cambs, UK), $\beta$-actin (1: 5000 , Proteintech), or histone H3 (1:1000, Abcam) at $4^{\circ} \mathrm{C}$ overnight. The membranes were washed with Tris Buffered Saline with Tween 3 times, followed by incubation with horseradish peroxidase-conjugated anti-mouse (1:10000, CST, Beverly, MA) or anti-rabbit antibody (1:5000, CST) for $1 \mathrm{~h}$ at room temperature. An enhanced chemiluminescence detection system (Beyotime Biotech) was used to detect the bands. Band densities were digitally quantified and normalized to $\beta$-actin or Histone H3 using Image J software (NIH, USA).

\section{Primary culture of rat cortical neuron culture and treatment}

Cortical neurons were obtained from the brains of one-day-old Sprague-Dawley rats as previously described with slight modifications [24]. Briefly, the cortexes of neonatal rats were dissected after the rats were deeply anaesthetized. The tissues were digested with $0.125 \%$ trypsin at $37^{\circ} \mathrm{C}$ for 30 min to release the neurons. The neurons were plated on culture dishes coated with $0.0125 \%$ poly-L-lysine in Neurobasal medium (Gibco, USA) with B27 (Gibco, USA). The cells were then placed in a humidified atmosphere of 5\% 
$\mathrm{CO}_{2}$ at $37^{\circ} \mathrm{C}$. One day later, neurons were pretreated with $\alpha$-LA $(1 \mu \mathrm{M}, 10 \mu \mathrm{M}, 100 \mu \mathrm{M})$ for $1 \mathrm{~h}$ followed by oxygen glucose deprivation (OGD) for $24 \mathrm{~h}$. Briefly, the neurons were placed into an anaerobic chamber (Thermo, MA), and the culture medium was replaced by a balanced salt solution $(5.4 \mathrm{mM} \mathrm{KCl}, 116 \mathrm{mM}$ $\mathrm{NaCl}, 1 \mathrm{mM} \mathrm{NaH} \mathrm{PO}_{4}, 26.2 \mathrm{mM} \mathrm{NaHCO}, 1.8 \mathrm{mM} \mathrm{CaCl}_{2}, 5 \mathrm{mM}$ HEPES, $\mathrm{pH} 7.4$ ). The oxygen in the chamber was replaced with nitrogen. At the end of the OGD, the medium was replaced with the original medium in a humidified atmosphere of $5 \% \mathrm{CO}_{2}$ and $95 \%$ air at $37^{\circ} \mathrm{C}$ for $24 \mathrm{~h}$.

The cells were randomly divided into eight groups: (1) Sham group (cells did not undergo OGD/ reoxygenation); (2) Control group (cells only underwent OGD/reoxygenation); (3) LA $1 \mu$ M group: pretreated with $1 \mu \mathrm{M} \alpha$-LA $1 \mathrm{~h}$ before OGD/reoxygenation; (4) LA $10 \mu \mathrm{M}$ group: pretreated with $10 \mu \mathrm{M} \alpha$-LA $1 \mathrm{~h}$ before OGD/reoxygenation; (5) LA $100 \mu \mathrm{M}$ group: pretreated with $100 \mu \mathrm{M} \alpha$-LA $1 \mathrm{~h}$ before OGD/reoxygenation; (6) si-Nrf2 group: cells were infected with siRNA-Nrf2 lentivirus $48 \mathrm{~h}$ before and pretreated with $100 \mu \mathrm{M}$ $\alpha$-LA $1 \mathrm{~h}$ before OGD/reoxygenation; (7) si-HO-1 group: cells were infected with si-RNA-HO- 1 lentivirus 48 $\mathrm{h}$ before and pretreated with $100 \mu \mathrm{M} \alpha$-LA $1 \mathrm{~h}$ before OGD/reoxygenation; (8) si-control group: cells were infected with nontargeting scramble siRNA lentivirus $48 \mathrm{~h}$ before and pretreated with $100 \mu \mathrm{M} \alpha$-LA $1 \mathrm{~h}$ before OGD/reoxygenation. The RNAi target sequences for si-Nrf2, si-HO-1 (Nrf2: 5'-gctcagaactgtaggaaaa-3' and HO-1:5'- cgaccgtggcagtgggaat-3') were designed according to the NCBI Gen Bank. According to the target sequences, the shRNA oligonucleotides (

Nrf2 SH-1: 5'-gatccgctcagaactgtaggaaaaTTCAAGAGAttttcctacagttctgagcTTTTTTg-3',

Nrf2 SH-2: 5'-aattcAAAAAAgctcagaactgtaggaaaaTCTCTTGAAttttcctacagttctgagcg-3',

HO-1 SH-1: 5'-gatccgcgaccgtggcagtgggaatTTCAAGAGAattcccactgccacggtcgTTTTTTg-3',

HO-1 SH-2: 5'- aattcAAAAAACgaccgtggcagtgggaatTCTCTTGAAattcccactgccacggtcgcg-3', and control SH-1:

5'-gatccGTAGCGCGGTGTATTATACTTCAAGAGAGTATAATACACCGCGCTACTTTTTTg-3', control SH-2: 5'-aattcAAAAAAGTAGCGCGGTGTATTATACTCTCTTGAAGTATAATACACCGCGCTACg-3') were annealed to double-stranded shRNA. The double-stranded shRNA was cloned into the lentiviral vector hU6-MCS-CMVPuro (Hanyinbt, Shanghai, China) by restriction endonuclease BamH I and EcoR I (Fermentas, Ontario, Canada) double digestion and T4 DNA ligase (Fermentas, Ontario, Canada) ligation. The packaging plasmids and the recombinant plasmid were co-transfected into 293T cells (ATCC, MA) using lipofectamine 3000 (Life, CA) to produce lentiviral particles. The knockdown efficiency was determined by western blot analysis.

\section{Cell viability}

Cell viability was measured using CCK8 (DojinDo, Tokyo, Japan) at $24 \mathrm{~h}$ after OGD as described previously [25] by observers who were blinded to the experimental groups. Briefly, $10 \mu \mathrm{l} \mathrm{CCK8}$ was added to each culture well and then the neurons were incubated at $37^{\circ} \mathrm{C}$ for $2 \mathrm{~h}$. The absorbance at $450 \mathrm{~nm}$ was measured using an absorbance reader (ELx808; Biotek, VT). The viability of the neurons was expressed as the percentage of the Sham group.

\section{Measurement of induced intracellular ROS levels}

Intracellular ROS was assessed by an oxidation-sensitive fluorescent probe (DCFH-DA) with a commercial Reactive Oxygen Species Assay Kit (Beyotime) at $24 \mathrm{~h}$ post OGD according to the manufacturer's instructions by observers who were blinded to the experimental groups. Briefly, the cells were incubated with $10 \mu \mathrm{M}$ DCFH-DA at $37^{\circ} \mathrm{C}$ for $20 \mathrm{~min}$. The DCFH-DA passed through the cell membrane freely and was deacetylated by nonspecific esterases. The DCFH-DA was degraded to DCFH, which could be oxidized by intracellular ROS to the fluorescent compound DCF. DCF fluorescence was detected using a fluorescence microplate reader (FLX800, Biotek, VT) at an excitation of $488 \mathrm{~nm}$ and an emission of $525 \mathrm{~nm}$.

\section{Immunofluorescence staining for Nrf2 and HO-1}

Primary neurons were fixed with 4\% paraformaldehyde and washed with PBS 3 times. Triton X-100 (0.5\%) was used for permeabilization. The cells were incubated with anti-HO-1 (1:100; Proteintech), antiNrf2 (1:200; Abcam) and anti-NeuN (1:100; Abcam) at $4^{\circ} \mathrm{C}$ overnight. After washing with PBST, the cells were incubated with anti-rabbit-IgG (1:1000; Invitrogen) or anti-mouse-IgG (1:1000; Invitrogen) for $1 \mathrm{~h}$ at room temperature, followed by washing with PBS and then incubation with DAPI (1:10000; Beyotime) for 2 min. A fluorescence microscope (CKX41, Tokyo, Japan) was used to view the images by observers who were blinded to the experimental groups.

\section{KARGER}




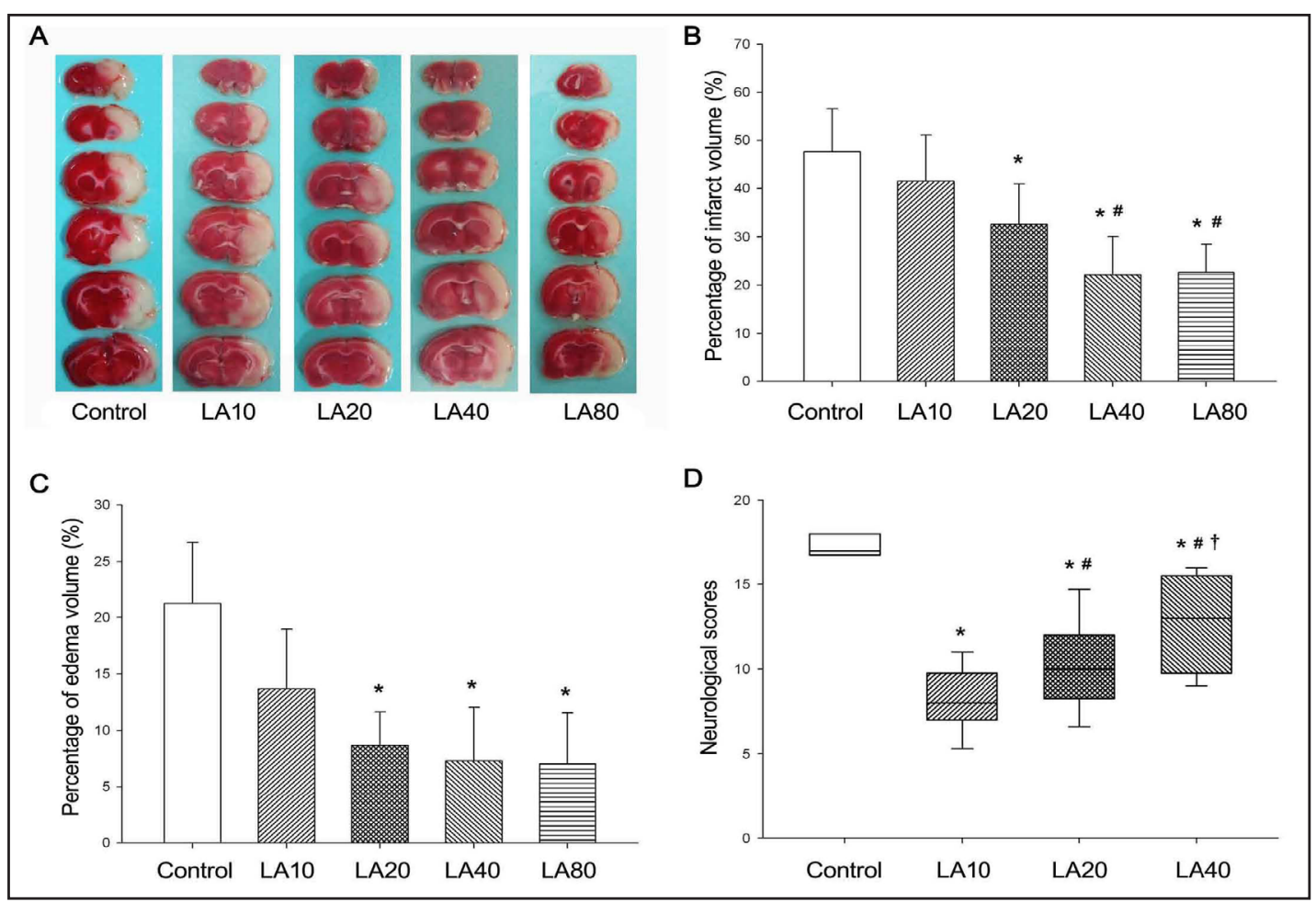

Fig. 1. $\alpha$-LA decreases the infarct volume and brain edema and improves the neurological outcome in the MCAO model. The brains were collected and stained with TTC $24 \mathrm{~h}$ after reperfusion. Representative samples of TTC-stained brain slices (A). Statistical analysis of the percentage of infarct volume (B). The percentage of brain edema in each group (C). The 18-point Garcia score was used to evaluate the sensor motor function at $24 \mathrm{~h}$ after reperfusion (D). For TTC and edema evaluation: ${ }^{*} \mathrm{P}<0.05$ vs. control group, ${ }^{\#} \mathrm{P}<0.05$ vs. LA10 group. For neurologic scoring: ${ }^{*} \mathrm{P}<0.05$ vs. sham group, ${ }^{*} \mathrm{P}<0.05$ vs. control group, ${ }^{\dagger} \mathrm{P}<0.05$ vs. LA2 20 group.

\section{Statistical Analysis}

The neurological deficit scores were expressed as the medians and interquartile ranges (25th to 75th percentiles) and analyzed with the Kruskal-Wallis test, which was followed by the post-hoc Mann-Whitney $\mathrm{U}$ test when the overall Kruskal-Wallis result was significant. Other data are presented as the means \pm SD and analyzed by one-way ANOVA, with Bonferroni correction for post hoc comparisons between multiple experimental groups. $P<0.05$ was considered to be significant. Statistical analysis was performed using SPSS ${ }^{\circledR}$ software (SPSS Inc., Chicago, IL).

\section{Results}

$\alpha$-LA reduces infarct size and cerebral edema and improves the neurological outcome of middle cerebral artery occlusion (MCAO)

To assess the neuroprotective effects of $\alpha$-LA, we evaluated infarct volumes after application of a range of doses of $\alpha$-LA in the MCAO rat model. Compared with the Control group $(47.6 \pm 8.9 \%)$, the infarct volumes in the LA20 group (32.7 $\pm 8.7 \%)$ and LA40 group $(22.2 \pm 7.9 \%)$ and LA80 group $(22.7 \pm 5.8 \%)$ were distinctly reduced (all $P<0.05)$ (Fig. $1 \mathrm{~A}$ and B). Among the $\alpha$-LA groups, the infarct volume in the LA40 and LA80 group was significantly decreased compared to the infarct volume in the LA20 group (41.6 $\pm 9.6 \%)(P<$ $0.05)$. However, no statistical differences were observed between the LA40 group and LA80 group.

To verify the protective effects of $\alpha$-LA, we assessed the levels of edema after MCAO. The cerebral water content at $24 \mathrm{~h}$ after reperfusion was $8.7 \pm 3.0 \%$ in the LA20 group and $7.3 \pm$ $4.7 \%$ in the LA40 group, all of which were significantly alleviated as compared to the Control 
group $(21.2 \pm 5.5 \%$ ) (all $P<0.05)$ (Fig. 1C). There was no significant difference between the LA40 group and the LA80 group. Based on these results, the LA20 and LA40 group were selected for further study.

We assessed the Garcia score to evaluate the sensor motor function after MCAO. No obvious neurological deficits were observed in the Sham operation group $(17[17,18])$, though the Garcia score in the Control group $(8[7,10])$ decreased significantly when compared with the Sham group $(P<0.05)$ (Fig. 1D). Compared with the Control group, the LA20 group (10 [8, $12])$ and LA40 group $(13[10,15])$ had significantly improved neurological outcomes (both $P<0.05)$. There was a statistical difference between the LA20 and LA40 groups, with the Garcia score in the LA40 group significantly improved $(P<0.05)$. These results suggest that $\alpha$-LA reduces the infarct volume, edema and neurological outcome of MCAO, with optimal neuroprotective effects observed at $40 \mathrm{mg} / \mathrm{kg} \alpha$-LA.

\section{$\alpha$-LA attenuates oxidative stress after MCAO}

To assess the mechanism of $\alpha$-LA in protecting rats from the detrimental effects of MCAO, we examined the activity of the antioxidant enzymes SOD and glutathione peroxidase (GSHPx) at 24 h post MCAO. As shown in Fig. 2A, the SOD activity decreased in the control group (33.0 $\pm 18.08 \mathrm{U} / \mathrm{mg}$ protein) compared with the Sham group (78.50 $\pm 16.18 \mathrm{U} / \mathrm{mg}$ protein) $(P<0.05)$. However, compared with the Control group, the SOD activity was increased in the LA20 group ( $54.33 \pm 21.91 \mathrm{U} / \mathrm{mg}$ protein) and LA40 group (70.33 $\pm 26.12 \mathrm{U} / \mathrm{mg}$ protein, $P<0.05$ ). Similar results were observed for GSH-Px activity (sham group, $56.0 \pm 7.92 \mathrm{U} / \mathrm{mg}$ protein; control group, $18.17 \pm 4.54 \mathrm{U} / \mathrm{mg}$ protein; LA20 group, $25.33 \pm 6.62 \mathrm{U} / \mathrm{mg}$ protein; LA40 group, $37.67 \pm 7.94 \mathrm{U} / \mathrm{mg}$ protein) (Fig. 2B). Furthermore, the GSH-Px activity in the LA40 group was significantly increased as compared to the LA20 group $(P<0.05)$. These results suggest that $\alpha$-LA partially reverses the suppression of antioxidant activity caused by MCAO.

To verify the effects of $\alpha$-LA on oxidative activity, we also assessed the content of the oxidative stress marker malondialdehyde (MDA). As shown in Fig. 2C, the MDA content in the

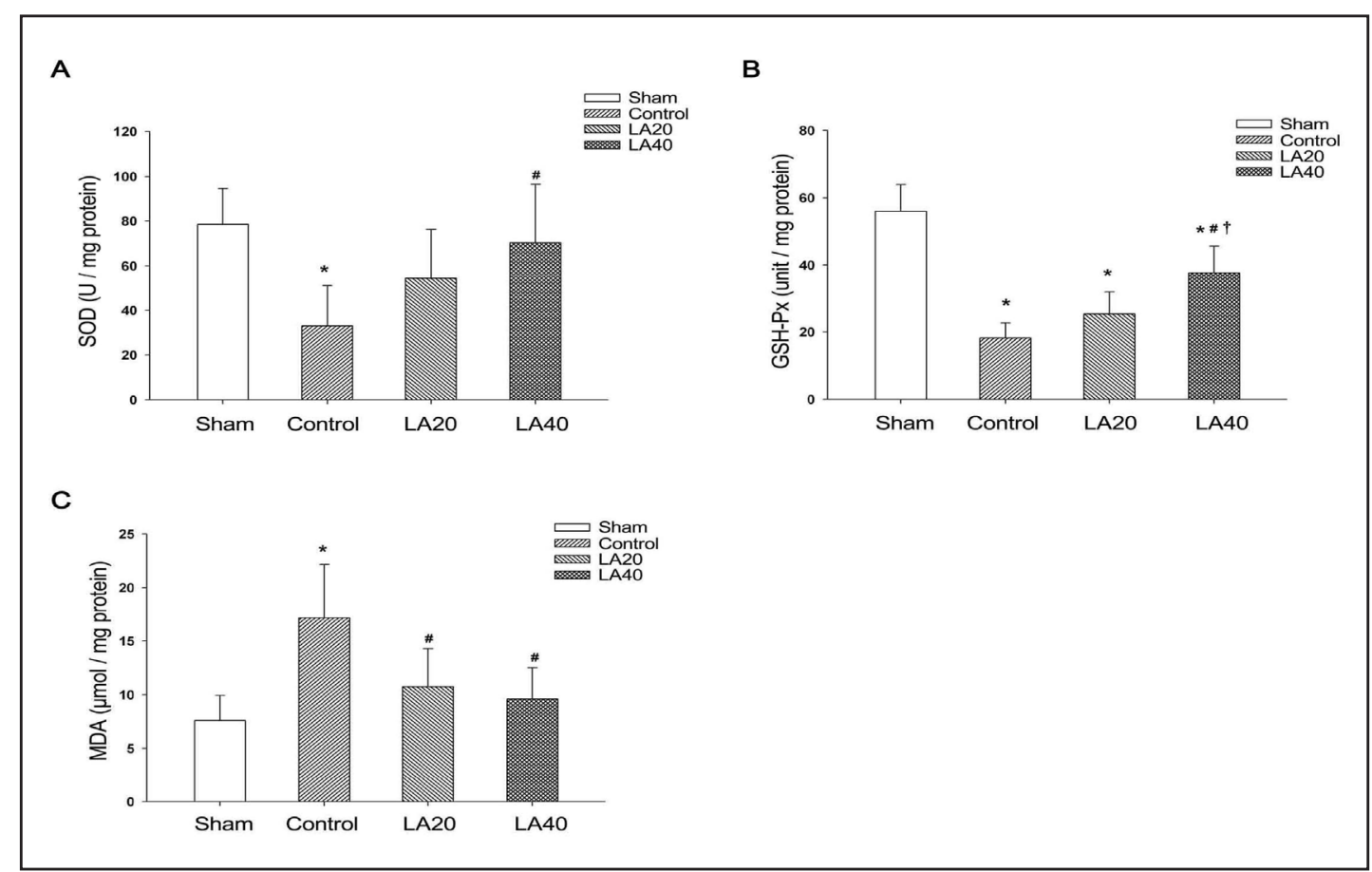

Fig. 2. $\alpha$-LA decreases oxidative damage in the MCAO model. The activity of SOD was assessed (A). The activity of GSH-Px was investigated (B). The content of the MDA was evaluated (C). ${ }^{*} \mathrm{P}<0.05$ vs. sham group, ${ }^{\sharp} \mathrm{P}<0.05$ vs. control group, ${ }^{\dagger} \mathrm{P}<0.05$ vs. LA20 group. SOD, superoxide dismutase; MDA, malondialdehyde; GSH-Px, glutathione peroxidase.

\section{KARGER}


Control group $(17.17 \pm 4.99 \mu \mathrm{mol} / \mathrm{mg}$ protein $)$ was upregulated significantly compared with the sham group $(7.58 \pm 2.35 \mu \mathrm{mol} / \mathrm{mg}$ protein $)(P<0.05)$. Furthermore, the upregulation was inhibited by the $\alpha$-LA treatment $(10.75 \pm 3.55 \mu \mathrm{mol} / \mathrm{mg}$ protein in LA20 group and 9.58 $\pm 2.94 \mu \mathrm{mol} / \mathrm{mg}$ protein in LA40 group, both $P<0.05$ ). Collectively, these results suggest that $\alpha$-LA attenuates the oxidative stress caused by MCAO.

$\alpha$-LA promotes the Nrf2 nuclear translocation and $\mathrm{HO}-1$ expression after MCAO

The transcriptional activator Nrf2 translocates to the nucleus upon activation and induces the expression of key metabolic genes, including antioxidants. To determine whether $\alpha$-LA modulates the activation of Nrf2, we assessed the effects of $\alpha$-LA on Nrf2 nuclear localization. As shown in Fig. 3A, an increase in the nuclear/cytoplasmic ratio was observed

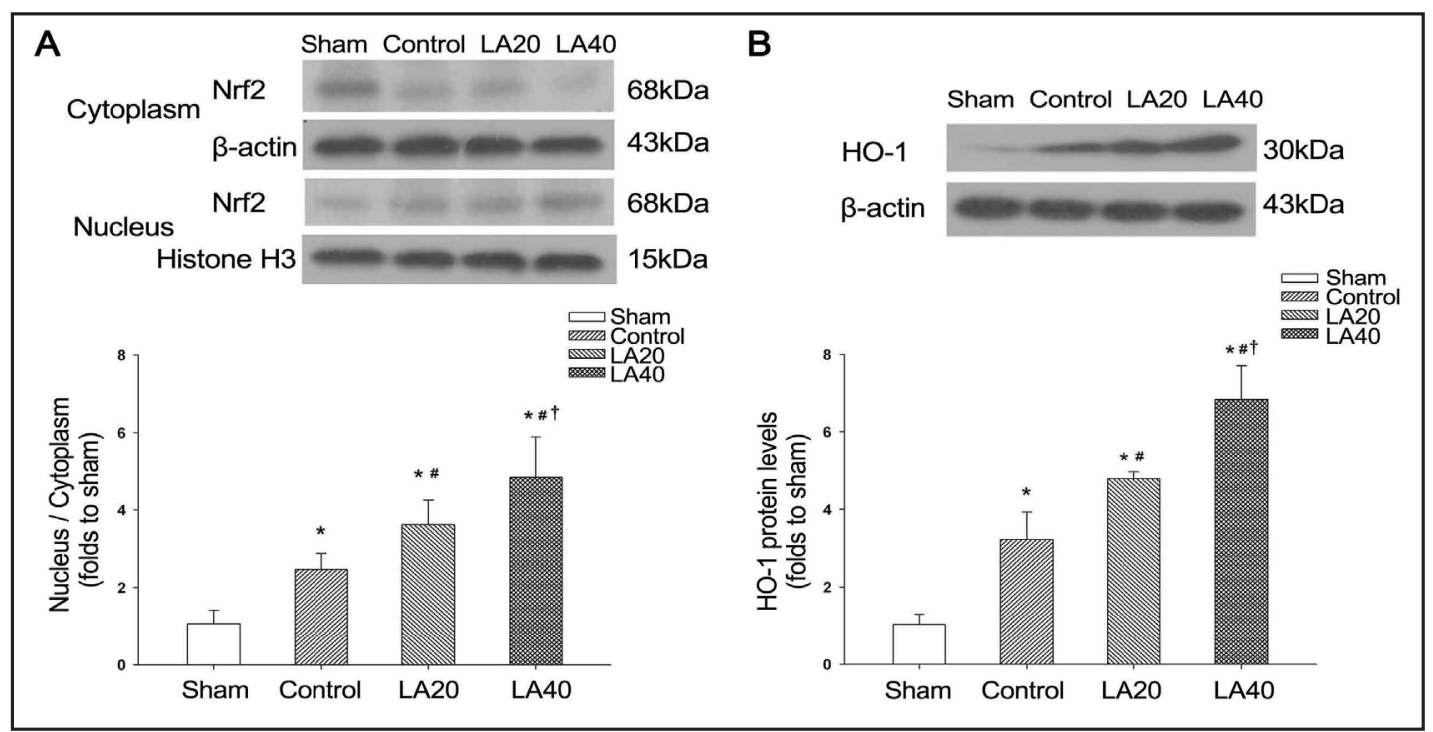

Fig. 3. $\alpha$-LA promotes Nrf2 nuclear translocation and HO-1 expression in the MCAO model. Tissue from the penumbra was collect at $24 \mathrm{~h}$ after reperfusion and used for western blot analysis. ${ }^{*} \mathrm{P}<0.05 \mathrm{vs}$. sham group, ${ }^{\#} \mathrm{P}<0.05$ vs. control group, ${ }^{\dagger} \mathrm{P}<0.05$ vs. LA20 group. Nrf2, factor-erythroid 2-related factor-2; HO-1, heme oxygenase-1.
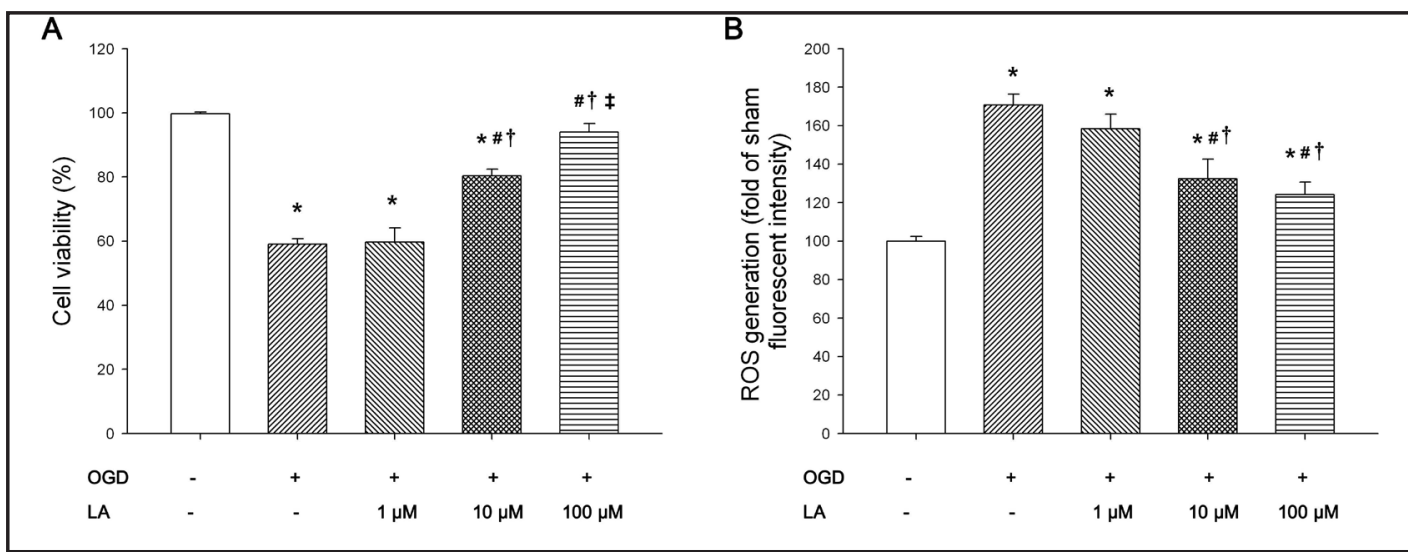

Fig. 4. Pretreatment of primary cortical neurons with $\alpha$-LA increases the cell viability and decreases the intracellular ROS. The cell viability and the intracellular ROS were assessed at $24 \mathrm{~h}$ post reoxygenation. Cell viability in the presence and absence of OGD and $\alpha$-LA (A). The levels of intracellular ROS in the presence and absence of OGD and $\alpha$-LA (B). ${ }^{*} \mathrm{P}<0.05$ vs. sham group, ${ }^{\#} \mathrm{P}<0.05$ vs. control group, ${ }^{\dagger} \mathrm{P}<0.05$ vs. LA $1 \mu \mathrm{M}$ group, ${ }^{\ddagger} \mathrm{P}<0.05$ vs. LA $10 \mu \mathrm{M}$ group. OGD, oxygen glucose deprivation.

\section{KARGER}




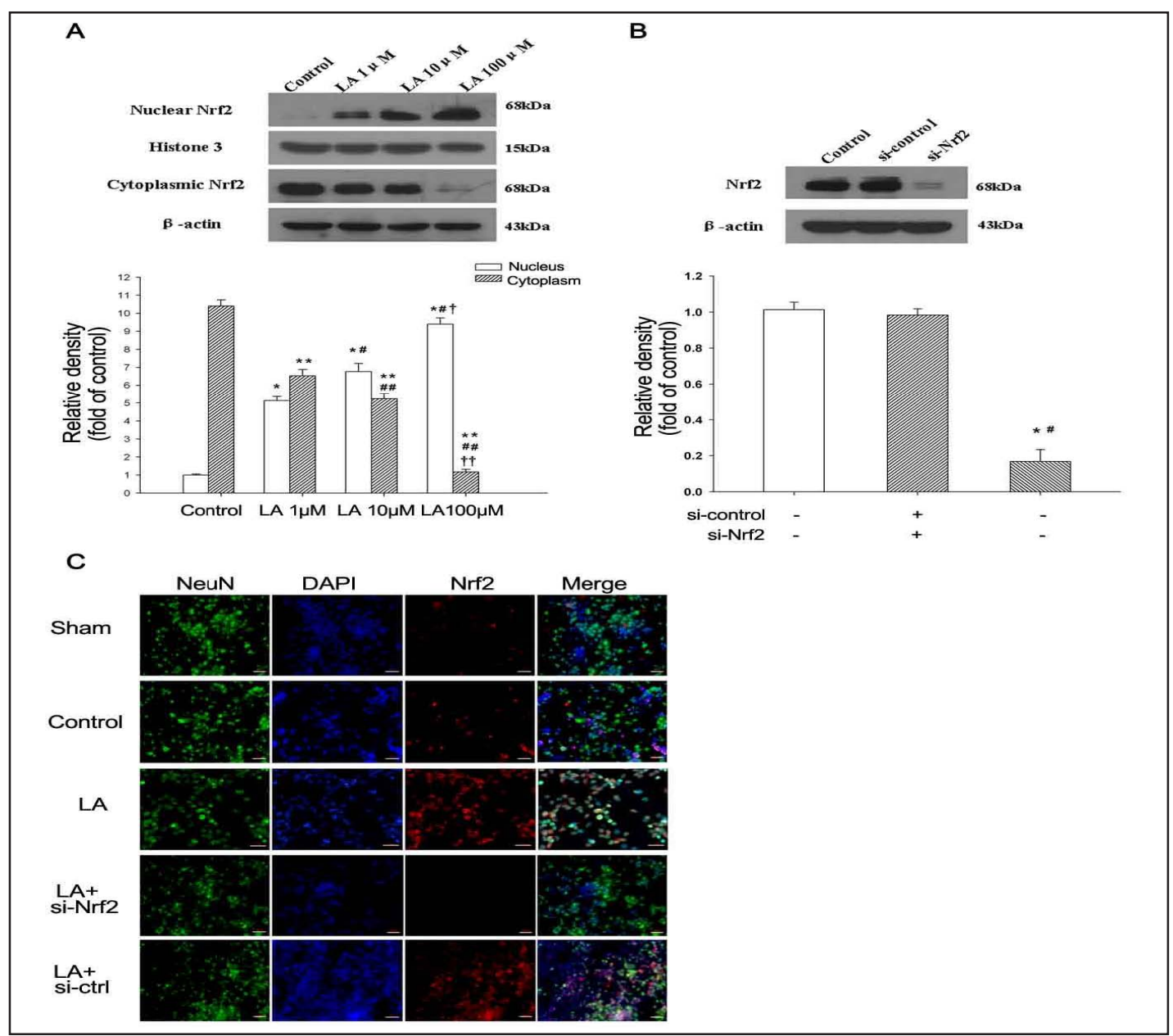

Fig. 5. $\alpha$-LA promotes Nrf2 nuclear translocation in primary cortical neurons in a concentration-dependent manner. (A) Primary cortical neurons were pretreated with media (Control) or $\alpha$-LA (1 $\mu \mathrm{M}, 10 \mu \mathrm{M}, 100 \mu \mathrm{M})$ $1 \mathrm{~h}$ before OGD. Cells were collected at $24 \mathrm{~h}$ after OGD and the cytoplasmic and nuclear protein were extracted for western blot analysis. For nucleus: ${ }^{*} \mathrm{P}<0.05$ vs. control group, ${ }^{*} \mathrm{P}<0.05$ vs. LA $1 \mu \mathrm{M}$ group, ${ }^{\mathrm{t}} \mathrm{P}<0.05$ vs. LA $10 \mu \mathrm{M}$ group. For cytoplasm: ${ }^{* *} \mathrm{P}<0.05$ vs. Control group, ${ }^{\# \#} \mathrm{P}<0.05$ vs. LA $1 \mu \mathrm{M}$ group, ${ }^{\dagger+} \mathrm{P}<0.05$ vs. LA $10 \mu \mathrm{M}$ group. (B) Lentivirus particles bearing si-Nrf2 were added into the LA $100 \mu \mathrm{M}$ group $48 \mathrm{~h}$ before OGD. The knock down efficiency of Nrf2 was evaluated by western blot analysis of whole cell lysates. ${ }^{*} \mathrm{P}<0.05$ vs. Control group, ${ }^{\#} \mathrm{P}<0.05$ vs. LA $100 \mu \mathrm{M}$ group, ${ }^{\dagger} \mathrm{P}<0.05$ vs. si-Nrf2 group. (C) Primary cortical neurons were left untreated (Sham) or treated with saline (Control) or $\alpha$-LA (100 $\mu \mathrm{M}) 1 \mathrm{~h}$ before OGD. Where indicated, the cells were also infected with si-Nrf2 or si-ctrl lentiviral particles. After $24 \mathrm{~h}$ OGD, cells were immunostained for the cytoplasmic neuronal marker NeuN (green), nuclear DNA (DAPI, blue) and Nrf2 (red). A fluorescence microscope was used to view the images. All images were captured at $400 \times$ magnification. Scale bar indicates $100 \mu \mathrm{m}$.

in the Control group ( $2.47 \pm 0.41$ fold of Sham, $P<0.05$ ), LA20 group ( $3.62 \pm 0.63$ fold of Sham, $P<0.05)$ and LA40 group ( $4.83 \pm 1.06$ fold of Sham, all $P<0.05)$, suggesting that the Nrf2 translocates to nucleus after MCAO. The nuclear/cytoplasmic ratio of Nrf2 in the LA40 and LA20 groups were significantly increased as compared to the control group (both $P<$ 0.05). Furthermore, the nuclear/cytoplasmic ratio of Nrf2 in the LA40 group was increased to a greater extent than it was in the LA20 group $(P<0.05)$. These results indicate that MCAO causes an increase in nuclear Nrf2, and this increase is enhanced by $\alpha$-LA.

To determine whether HO-1 is activated by MCAO and whether it is further activated by $\alpha$-LA after MCAO, we performed western blot analysis for HO-1. As shown in Fig. 3B, a 


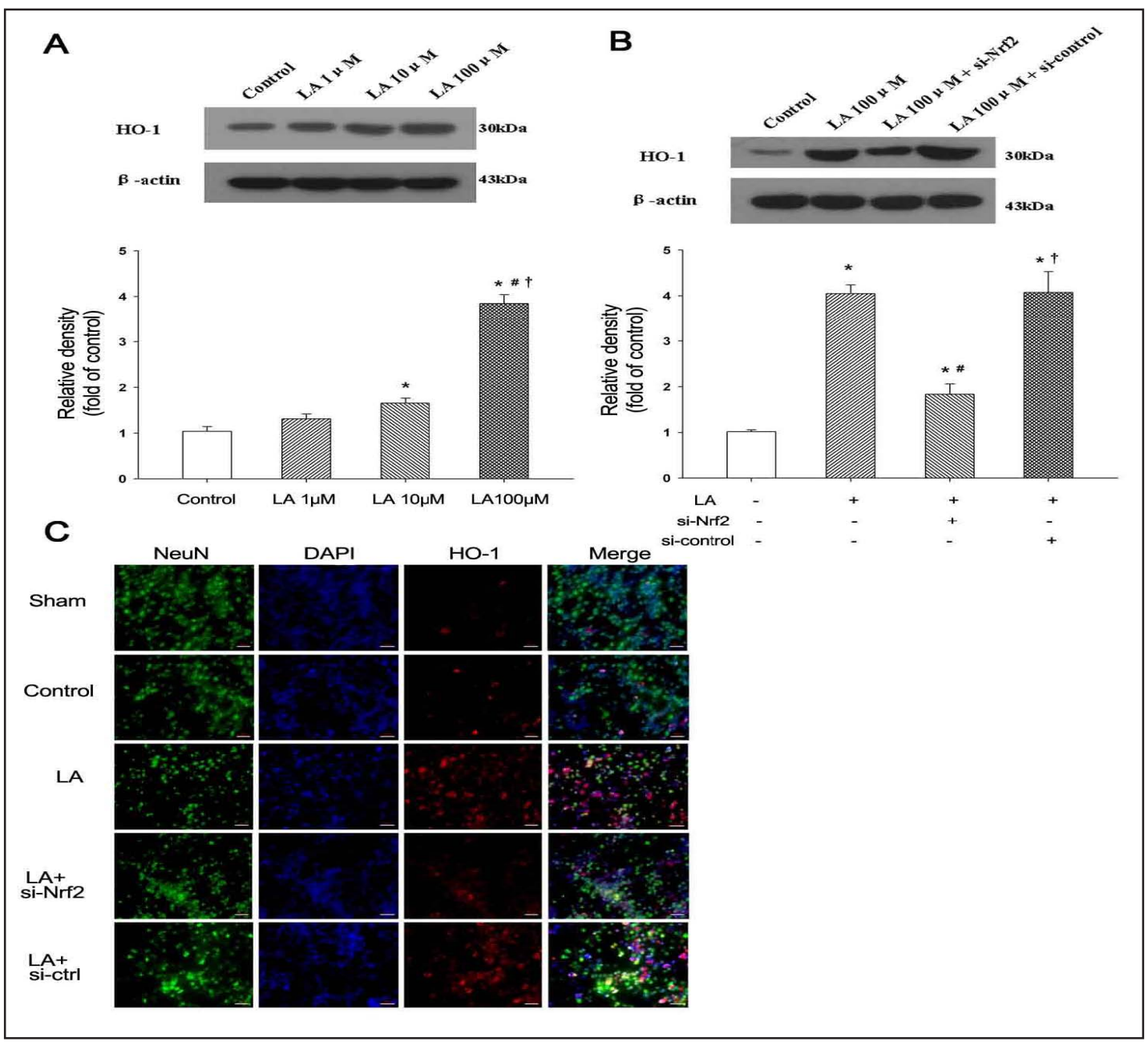

Fig. 6. $\alpha$-LA promotes HO-1 expression in primary cortical neurons in a Nrf2-dependent manner. (A) Primary cortical neurons were pretreated with media (Control) or $\alpha$-LA $(1 \mu \mathrm{M}, 10 \mu \mathrm{M}, 100 \mu \mathrm{M}) 1 \mathrm{~h}$ before OGD. Whole cell lysates were extracted at $24 \mathrm{~h}$ after OGD for western blot analysis. ${ }^{*} \mathrm{P}<0.05$ vs. Control group, ${ }^{\#} \mathrm{P}<0.05$ vs. LA $1 \mu \mathrm{M}$ group, ${ }^{\dagger} \mathrm{P}<0.05$ vs. LA $10 \mu \mathrm{M}$ group. (B) Lentivirus particles bearing si-Nrf2 were added to the LA $100 \mu \mathrm{M}$ group $48 \mathrm{~h}$ before OGD. The effect on HO-1 expression was evaluated by western blot analysis. ${ }^{*} \mathrm{P}<0.05$ vs. Control group, ${ }^{\#} \mathrm{P}<0.05$ vs. LA $100 \mu \mathrm{M}$ group, ${ }^{\dagger} \mathrm{P}<0.05$ vs. si-Nrf2 group. (C) Primary cortical neurons were left untreated (Sham) or pretreated with $\alpha$-LA $(100 \mu \mathrm{M}) 1 \mathrm{~h}$ before OGD. Where indicated, the cells were also infected with si-Nrf2 or si-ctrl lentiviral particles. After $24 \mathrm{~h}$ OGD, cells were immunostained for the cytoplasmic neuronal marker NeuN (green), nuclear DNA (DAPI, blue) and HO-1 (red). A fluorescence microscope was used to view the images. All images were captured at 400× magnification. Scale bar indicates $100 \mu \mathrm{m}$.

significant increase of HO-1 protein in the control group $(3.22 \pm 0.70$ fold of Sham, $P<0.05)$ was detected at $24 \mathrm{~h}$ after reperfusion. Treatment with $20 \mathrm{mg} / \mathrm{kg} \alpha$-LA (4.78 \pm 0.18 fold of Sham, $P<0.05)$ or $40 \mathrm{mg} / \mathrm{kg} \alpha$-LA $(6.83 \pm 0.88$ fold of Sham, $P<0.05)$ further elevated the HO-1 level. Compared with the LA20 group, the expression of HO-1 in the LA40 group was significantly increased $(P<0.05)$.

LA increases cell viability of cultured neurons and decreases the intracellular ROS induced by in vitro oxygen glucose deprivation (OGD)

To further investigate the underlying molecular mechanisms involved in LA-induced effects, we established an in vitro model in which primary rat cortical neurons were pretreated with $1 \mu \mathrm{M}, 10 \mu \mathrm{M}$ or $100 \mu \mathrm{M} \alpha$-LA for $1 \mathrm{~h}$ and then subjected to OGD. The viability 
of the Control group decreased significantly $(59.0 \pm 1.7 \%)$ compared with the Sham group $(P<0.05)$ after $24 \mathrm{~h}$ culture, and this decrease was reversed in a concentration-dependent manner by $\alpha$-LA treatment (Fig. 4A). The cell viability in the LA $10 \mu \mathrm{M}$ group $(80.3 \pm 2.1 \%$, $P<0.05)$ and the LA $100 \mu \mathrm{M}$ group $(94.0 \pm 2.6 \%, P<0.05)$ were increased significantly compared with the control group; however, the cell viability of the LA $1 \mu \mathrm{M}$ group (59.7 $\pm 4.51 \%$ ) was not significantly greater than the control. These results suggest that $\alpha$-LA protects neurons from OGD-induced cell death, with the highest cell viability restoration observed at $100 \mu \mathrm{M} \alpha$-LA.

To assess whether the effects of $\alpha$-LA on cell viability might be related to its ability to attenuate oxidative stress, we also measured ROS generation. As shown in Fig. 4B, a significant increase was observed in the intracellular ROS levels in the Control group (170.8 $\pm 5.7)$ as compared with the Sham group $(P<0.05)$. However, the OGD-induced increase of intracellular ROS levels was attenuated by $\alpha$-LA pretreatment in a concentration-dependent manner. Compared with control group and LA $1 \mu \mathrm{M}$ group (158.4 \pm 7.5 ), the ROS levels in the LA $10 \mu \mathrm{M}$ group $(132.4 \pm 10.1$, both $P<0.05)$ and LA $100 \mu \mathrm{M}$ group $(124.2 \pm 6.5$, both $P$ $<0.05$ ) were significantly decreased. Therefore, $\alpha$-LA protects cells from oxidative stress in vitro.

\section{LA promotes Nrf2 nuclear translocation in cultured neurons in a concentration-dependent} manner

To determine whether LA activates Nrf2 in cultured neurons, we performed western blotting after OGD. As shown in Fig. 5A, LA increased the nuclear Nrf2 level in a concentration dependent manner (LA $1 \mu \mathrm{M}$ group: $5.1 \pm 0.2$ fold of control group; LA $10 \mu \mathrm{M}$ group: $6.8 \pm 0.5$ fold of control group; LA $100 \mu \mathrm{M}$ group: $9.4 \pm 0.3$ fold of control group; all $P<0.05$ ). However, cytoplasmic Nrf2 was decreased by $\alpha$-LA, suggesting that the increase in nuclear Nrf2 may be explained, in part, by translocation of Nrf2. Compared with the control group (10.4 \pm 0.3$)$, the levels of cytoplasmic Nrf2 decreased significantly in the LA $1 \mu \mathrm{M}$ group $(6.5 \pm 0.4, P<$ $0.05)$, LA $10 \mu \mathrm{M}$ group (5.2 $\pm 0.3, P<0.05)$, and LA $100 \mu \mathrm{M}$ group $(1.2 \pm 0.2, P<0.05)$ in a dose dependent manner.

To verify the induction of Nrf2 nuclear translocation by LA, we prepared lentivirus bearing si-Nrf2 to specifically knock down gene expression in cultured neurons. Knockdown of Nrf2 protein was verified by western blotting (si-Nrf2, $0.17 \pm 0.07$ fold of Control; sicontrol group, $0.98 \pm 0.04$ fold of Control) (Fig. 5B). Next, we performed immunofluorescent microscopy of neurons with and without lentiviral knockdown. Our results show that Nrf2 was barely expressed in the Sham group, was moderately expressed in the control group, and was strongly expressed in the LA treatment group (Fig. 5C). The staining was inhibited by Nrf2 knockdown, which verifies the specificity of immunostaining. Nrf2 was expressed mostly in the nucleus, as visualized by the overlap between the red staining (Nrf2) and the blue staining (DAPI), which confirms that the $\alpha$-LA promotes Nrf2 nuclear expression.

\section{LA promotes HO-1 expression in cultured neurons in a Nrf2-dependent manner}

To determine whether $\alpha$-LA enhances the upregulation of HO- 1 in cultured neurons after OGD, we also performed western blotting for HO-1. Consistent with the in vivo results, $\alpha$-LA treatment also led to enhanced HO-1 expression in a concentration-dependent manner after OGD (Fig. 6A). The expression of HO- 1 in the LA $100 \mu \mathrm{M}$ group (3.85 \pm 0.19 fold of control) and LA $10 \mu \mathrm{M}$ group (1.66 \pm 0.11 fold of control) was obviously elevated as compared to the expression in the $1 \mu \mathrm{M}$ group $(1.31 \pm 0.11$ fold of Control $)(P<0.05)$.

To confirm that HO-1 is activated downstream of Nrf2, we repeated the western blotting with siRNA-ctrl or si-Nrf2. As expected, neurons pretreated with $\alpha$-LA had elevated HO-1 expression ( $4.05 \pm 0.19$ fold of Control) $(P<0.05)$; however, the addition of si-Nrf2 decreased HO-1 expression significantly (1.83 \pm 0.23 fold of control) (Fig. 6B). To further confirm these findings, we performed immunofluorescence staining for HO-1. HO-1 was barely expressed in neurons of the Sham group, mildly expressed in the Control group, and strongly expressed in the LA treatment group (Fig. 6C). The HO-1 protein was mostly expressed in the cytoplasm; 


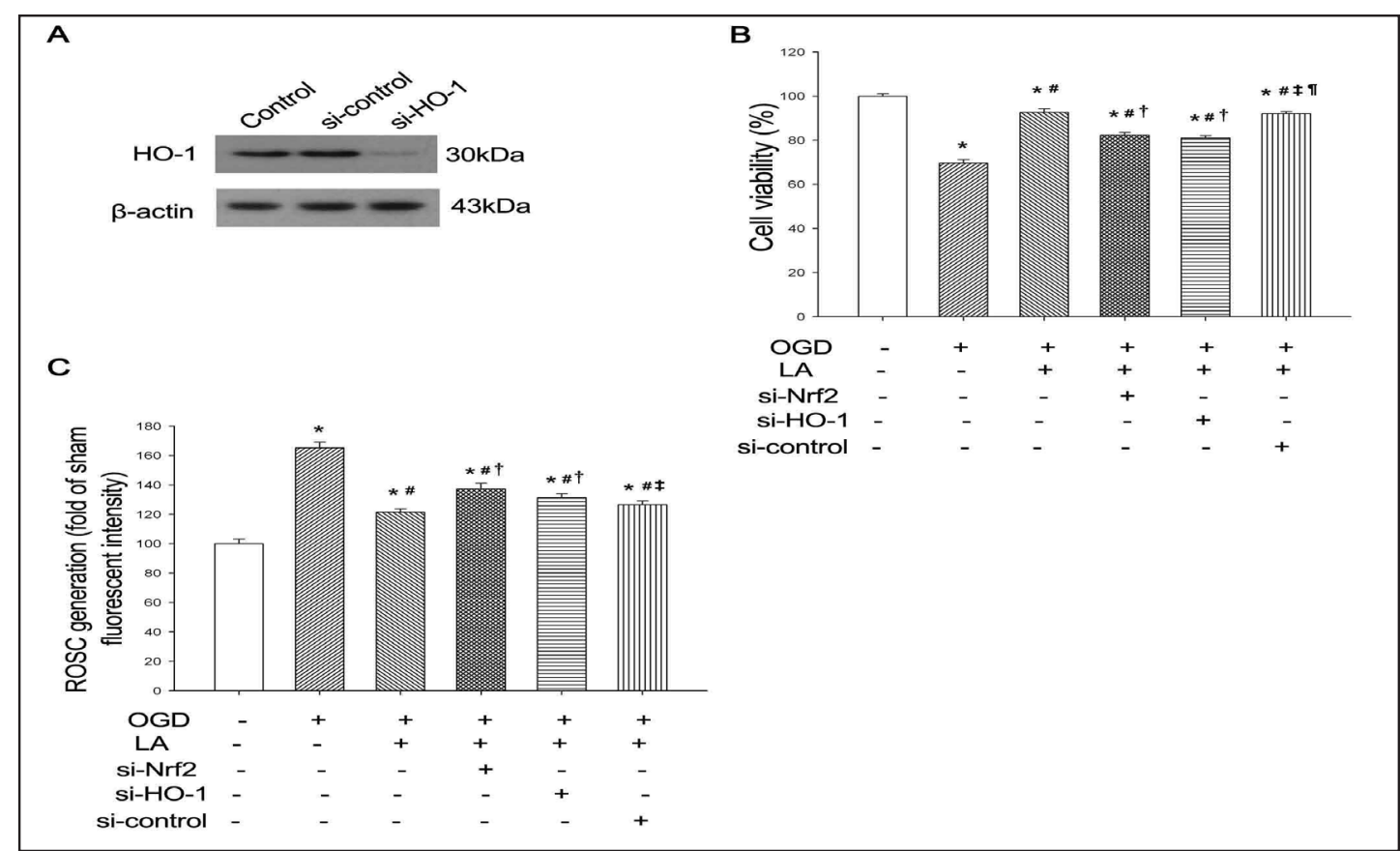

Fig. 7. The effect of $\alpha$-LA on ROS scavenging and cell viability of primary cortical neurons after OGD is Nrf2 and HO-1-dependent. (A) Primary cortical neurons were pretreated with $100 \mu \mathrm{M} \alpha$-LA 1 h before OGD (Control). Where indicated, Lentivirus particles bearing si-control or si-HO-1 were added $48 \mathrm{~h}$ before OGD. The knock down efficiency of HO- 1 was evaluated by western blot analysis. ${ }^{*} \mathrm{P}<0.05$ vs. Control group, ${ }^{\text {} P} \mathrm{P}<0.05$ vs. LA $100 \mu \mathrm{M}$ group, ${ }^{\dagger} \mathrm{P}<0.05$ vs. si-Nrf2 group. (B-C) Neurons were treated with OGD, $100 \mu \mathrm{M} \alpha$ - LA and/or siRNA as indicated. The cell viability (panel B) and ROS level (Panel C) were assessed at $24 \mathrm{~h}$ post reperfusion. ${ }^{*} \mathrm{P}<0.05$ vs. Sham group, ${ }^{\#} \mathrm{P}<0.05$ vs. Control group, ${ }^{\dagger} \mathrm{P}<0.05$ vs. LA $100 \mu \mathrm{M}$ group, ${ }^{\star} \mathrm{P}<0.05$ vs. si-Nrf2 group, ${ }^{\natural} \mathrm{P}<0.05$ vs. si-HO-1 group.

however, the elevated expression of HO-1 in the LA treatment group was blocked by si-Nrf2. These results confirm that $\alpha$-LA promotes the expression of HO-1 through the activation of Nrf2.

The in vitro neuronal protective effect of LA is dependent on the Nrf2/HO-1 pathway

To verify the role of Nrf2 and HO- 1 in the neuroprotective effect of $\alpha$-LA, we prepared an additional lentiviral vector to knock down HO-1 (Fig. 7A), and we then assessed the effects of both si-Nrf2 and si-HO on cell viability after OGD. As shown in Fig. 7B, the decrease in the viability of the control OGD group $(69.7 \pm 1.5 \%$ of Sham $)(P<0.05)$ was significantly inhibited by pretreatment with $\alpha$-LA $(92.7 \pm 1.5 \%$ of Sham, $P<0.05)$; however, knock down of Nrf2 or HO- 1 attenuated the effects of $\alpha$-LA treatment on cell viability $(82.3 \pm 1.2 \%$ of Sham, $81.0 \pm 1.0 \%$ of Sham, respectively) (both $P<0.05$ ). Similarly, the increase in ROS in the control group (165.2 $\pm 3.9 \%$ of Sham) was reduced by LA treatment (121.5 $\pm 2.3 \%$ of Sham); however, knock down of Nrf2 or HO-1 weakened the effect of $\alpha$-LA on ROS scavenging (137.3 $\pm 3.9 \%$ of Sham, $131.4 \pm 2.6 \%$ of Sham, respectively) (both $P<0.05$ ). These results suggest that Nrf2 and HO-1 are essential for the attenuating effects of $\alpha$-LA on cell viability and ROS production.

\section{Discussion}

Ischemic stroke accounts for $85 \%$ of all stroke cases [2], and the global burden attributed to stroke is on the rise [26]. Although intravenous tissue plasminogen activator is the standard treatment for stroke, a relatively short therapeutic time window $(<4.5 \mathrm{~h})$ limits its clinic use [3]. 
Lipoic acid acts as a cofactor in mitochondrial $\alpha$-keto acid dehydrogenase complexes in all eukaryotic and prokaryotic cells [27]. Previous studies demonstrated that exogenously supplied LA can pass through the blood brain barrier and accumulate in the brain $[28,29]$. These properties make LA a perfect antioxidant for the treatment of brain disease. The neuroprotective effect of LA has been demonstrated in different animal models of cerebral ischemia reperfusion injury [12, 30, 31]. Clark et al. [30] demonstrated that LA pretreatment $(100 \mathrm{mg} / \mathrm{kg}$, subcutaneously) significantly reduced stroke infarct volume and promoted neurological function at $24 \mathrm{~h}$ post reperfusion in a focal cerebral reperfusion model. Furthermore, in a retrospective clinical study, Choi et al. [13] demonstrated that favorable outcomes occurred at significantly higher rates both at 3 months and at 1 year in patients treated with LA.

Consistent with these previous findings, we showed that $20 \mathrm{mg} / \mathrm{kg}$ and $40 \mathrm{mg} / \mathrm{kg} \alpha$-LA administration significantly reduced the infarct volume and promoted neurological recovery in the present study. This result was validated in our in vitro model of OGD/reoxygenation. We demonstrated that cell viability was improved when the cultured neurons were pretreated with $\alpha$-LA. All of these results support the neuroprotective role of $\alpha$-LA. In addition, in this study, we make a further investigation about the effect of $\alpha$-LA in different concentrations. We discovered that with the increase of concentration, the protective effect of LA became more significant both in animal study and in vitro model. However, no statistical differences were observed between LA 40 and LA 80 group. Hence we infer that there might be a ceiling effect by using $\alpha$-LA against stroke. Future studies on different concentrations and durations are warranted to determine the optimum concentration and therapeutic schedule of $\alpha$-LA.

Previous studies have indicated that oxidative stress is involved in ischemic stroke, and attenuation of oxidative damage improves neurological outcome [32, 33]. MDA, a marker of lipid peroxidation, is one of the most commonly used indicators of oxidative stress [34]. SOD, which primarily resides in neurons, is important in clearing away the excessive ROS; and GSH-Px, which primarily resides in astrocytes, quickly metabolizes lipid peroxides to less toxic hydroxyl derivatives [29]. In this study, the content of MDA increased and the activity of SOD and GSH-Px decreased significantly after MCAO, which is consistent with the induction of oxidative stress. Furthermore, these changes were inhibited by $\alpha$-LA treatment. Similar results were also observed in vitro study. In the OGD/reoxygenation model, we found that the viability of the neurons was significantly decreased and the intracellular ROS was significantly increased compared with normal cells. Addition of LA to OGD/reoxygenationtreated cells resulted in significant increase of the viability of the cells and reduction of ROS levels. The current in vivo/ex vivo findings, in agreement with previous studies [28, 35], demonstrate that LA could exert its neuroprotection through the attenuation of oxidative stress injury.

Although the neuroprotective effect of $\alpha$-LA has been confirmed in animal experiments and clinical study, the mechanism underlying the protective effect of $\alpha$-LA was still poorly understood. In the study of Wu et al. [36], the neuroportective of $\alpha$-LA was attributed to inhibition of peripheral tumor necrosis factor-alpha and downregulation of brain microglial activation. In another research, the effect of $\alpha$-LA was partially attributed to activation of insulin receptor because HNMPA-(AM)3, an insulin receptor inhibitor, blocked the neurorestorative effects of $\alpha$-LA [12].

Nrf2 is a well-characterized nuclear factor that can regulate the expression of antioxidants such as HO-1 [37]. Under basal conditions, Nrf2 binds to Kelch-like ECH-associated protein 1 (Keap1) [38]. However, under conditions of stress, the association between Keap1 and Nrf2 is disrupted. Once freed from Keap1, Nrf2 translocates to the nucleus and activates the expression of HO-1 [39]. As a redox-sensitive inducible enzyme, HO-1 degrades heme into iron, carbon monoxide and the radical-scavenging molecules biliverdin/bilirubin [40]. Previous studies have demonstrated that HO-1 and its metabolites including carbon monoxide, $\mathrm{Fe}^{2+}$, biliverdin played important roles in antioxidant effect [40].

In a recent study, Deng et al. [14] found that LA pretreatment promoted Nrf2 nuclear accumulation and the induction of HO-1 in a rat myocardial ischemia/reperfusion injury 
model. To investigate whether Nrf2/HO-1 signaling is involved in the neuroprotective effect of $\alpha$-LA in brain, we investigated the expressions of Nrf2 and HO- 1 in rats suffered MCAO or in cortical neurons exposed to OGD/reoxygenation. In brain tissue, the expression and nuclear localization of Nrf2 was upregulated after MCAO, and that LA administration caused further elevation of nuclear expression. Similar results were found in primary cortical neurons in which LA increased the early nuclear translocation of Nrf2. A similar conclusion was made by Shi et al. [35] who found that LA regenerated reduced glutathione by activating Nrf2 signaling pathway via promoting the nuclear translocation of Nrf2 in cadmium-treated HepG2 cells. Valdecantos et al. [41] also demonstrated that LA induced an early nuclear translocation of Nrf2 in hepatocytes treated with palmitic acid in rats.

Furthermore, in this study, we found that the expression of HO-1 was significantly upregulated after MCAO with further elevated expression after $\alpha$-LA treatment. And similar results were also found in primary cortical neurons in which activated expression of HO-1 was observed after $\alpha$-LA treatment. The antioxidant HO-1 has been characterized to have Nrf2 binding elements in its promoter and to could be activated by Nrf2. Therefore, the present findings, in conjunction with these previously published data $[35,41]$, raise the hypothesis that $\mathrm{Nrf} 2 / \mathrm{HO}-1$ signaling is involved in the neuroprotective effect of $\alpha$-LA.

To further confirm the role of Nrf2/HO-1 pathway in the LA treatment process, the Nrf2 and HO-1 genes were knocked down using lentiviral particles. When neurons were pretreated with either siNrf2 or siHO-1, the protective effect of $\alpha$-LA, as assessed by cell viability and ROS generation was reduced. These results provide strong evidence that the $\alpha$-LA attenuates oxidative damage by activating the Nrf2/HO-1 pathway.

An interesting finding in our in vitro study is that although the protective effect of $\alpha$-LA was reduced significantly when neurons were pretreated with siNrf2 before OGD, the levels of cell viability and ROS generation had not gone back to the OGD levels. These findings might suggest that $\mathrm{Nrf} 2 / \mathrm{HO}-1$ is not the only pathway underlying the antioxidative protective effect of $\alpha$-LA. Further investigations on the other pathways involved in the antioxidative protective effect of $\alpha$-LA in brain protection are needed.

Previous studies have revealed that the therapeutic window of stroke is approximately 6 hours; after this window, irreversible neuronal death occurs [42]. In our study, the $\alpha$-LA was administrated intravenously immediately after the reperfusion, which is consistent with its potential clinical application. A dose-dependent neuroprotective effect of $\alpha$-LA was demonstrated in both the in vivo and in vitro studies. These results suggest that $\alpha$-LA may be useful for the treatment of acute ischemic stroke. However, the potential long-term effect of $\alpha$-LA warrants further study.

In conclusion, the present study demonstrated that $\alpha$-LA is neuroprotective and promotes functional recovery after ischemic stroke. Both in an MCAO in vivo model and an OGD in vitro model, $\alpha$-LA enhances the induction of Nrf2 translocation and HO-1 expression. Using lentiviral vectors to introduce si-Nrf2 and si-HO-1 into primary cortical neurons, we demonstrated that $\alpha$-LA exerts its neuroprotection by attenuating oxidative damage that is partially mediated by the $\mathrm{Nrf2/HO}-1$ pathway.

\section{Acknowledgements}

This study was supported by grants from the National Natural Science Foundation of China (81372026). The funders had no role in study design, data collection and analysis, decision to publish, or preparation of the manuscript.

\section{Disclosure Statement}

No competing financial interests exist. 


\section{Cellular Physiology Cell Physiol Biochem 2017;43:1273-1287 \begin{tabular}{l|l|l} 
and Biochemistry 10.1159/000481840 & $\begin{array}{l}\text { C } 2017 \text { The Author(s). Published by S. Karger AG, Basel } \\
\text { www.karger.com/cpb }\end{array}$ \\
\hline
\end{tabular}}

Lv et al.: $\alpha$-LA Activates Nrf2/HO-1 Pathway After Stroke

\section{References}

1 Krishnamurthi RV, Feigin VL, Forouzanfar MH, Mensah GA, Connor M, Bennett DA, Moran AE, Sacco RL, Anderson LM, Truelsen T, O’Donnell M, Venketasubramanian N, Barker-Collo S, Lawes CM, Wang W, Shinohara Y, Witt E1, Ezzati M, Naghavi M, Murray C, Global Burden of Diseases, Injuries, Risk Factors Study 2010 (GBD 2010), GBD Stroke Experts Group: Global and regional burden of first-ever ischaemic and haemorrhagic stroke during 1990-2010: findings from the Global Burden of Disease Study 2010 Lancet Glob Health. 2013;1:e259-e281.

-2 Gibson CL, Srivastava K, Sprigg N, Bath PM, Bayraktutan U: Inhibition of Rho-kinase protects cerebral barrier from ischaemia-evoked injury through modulations of endothelial cell oxidative stress and tight junctions. J Neurochem 2014;129: 816-826.

-3 Kleindorfer D, Lindsell CJ, Brass L, Koroshetz W, Broderick JP: National US estimates of recombinant tissue plasminogen activator use: ICD-9 codes substantially underestimate. Stroke 2008;39:924-928.

$\checkmark 4$ Deb P, Sharma S, Hassan KM: Pathophysiologic mechanisms of acute ischemic stroke: An overview with emphasis on therapeutic significance beyond thrombolysis. Pathophysiology 2010;17:197-218.

-5 Rodrigo R, Fernández-Gajardo R, Gutiérrez R, Matamala JM, Carrasco R, Miranda-Merchak A, Feuerhake W: Oxidative stress and pathophysiology of ischemic stroke: novel therapeutic opportunities. CNS Neurol Disord Drug Targets 2013;12:698-714.

6 Manzanero S, Santro T, Arumugam TV: Neuronal oxidative stress in acute ischemic stroke: sources and contribution to cell injury. Neurochem Int 2013;62:712-718.

7 Hanafy KA, Selim MH: Antioxidant strategies in neurocritical care. Neurotherapeutics 2012;9:44-55.

-8 Heo JH, Han SW, Lee SK: Free radicals as triggers of brain edema formation after stroke. Free Radic Biol Med 2005;39:51-70.

9 Oztanir MN, Ciftci O, Cetin A, Durak MA, Basak N, Akyuva Y: The beneficial effects of 18beta-glycyrrhetinic acid following oxidative and neuronal damage in brain tissue caused by global cerebral ischemia/ reperfusion in a C57BL/J6 mouse model. Neurol Sci 2014;35:1221-1228.

10 Packer L: alpha-Lipoic acid: a metabolic antioxidant which regulates NF-kappa B signal transduction and protects against oxidative injury. Drug Metab Rev 1998;30:245-275.

11 Wu MH, Huang CC, Chio CC, Tsai KJ, Chang CP, Lin NK, Lin MT: Inhibition of Peripheral TNF- $\alpha$ and Downregulation of Microglial Activation by Alpha-Lipoic Acid and Etanercept Protect Rat Brain Against Ischemic Stroke. Mol Neurobiol 2016;53:4961-4971.

12 Choi KH, Park MS, Kim HS, Kim KT, Kim HS, Kim JT, Kim BC, Kim MK, Park JT, Cho KH: Alpha-lipoic acid treatment is neurorestorative and promotes functional recovery after stroke in rats. Mol Brain 2015;8:9.

13 Choi KH, Park MS, Kim JT, Kim HS, Kim JH, Nam TS, Choi SM, Lee SH, Kim BC, Kim MK, Cho KH: Lipoic Acid Use and Functional Outcomes after Thrombolysis in Patients with Acute Ischemic Stroke and Diabetes. PLoS One 2016;11:e0163484.

14 Deng C, Sun Z, Tong G, Yi W, Ma L, Zhao B, Cheng L, Zhang J, Cao F, Yi D: $\alpha$-Lipoic acid reduces infarct size and preserves cardiac function in rat myocardial ischemia/reperfusion injury through activation of PI3K/ Akt/Nrf2 pathway. PLoS One 2013;8:e58371.

15 Kilkenny C, Browne W, Cuthill IC, Emerson M, Altman DG; NC3Rs Reporting Guidelines Working Group: Animal research: reporting in vivo experiments: the ARRIVE guidelines. Br J Pharmacol 2010;160:15771579.

16 McGrath JC, Drummond GB, McLachlan EM, Kilkenny C, Wainwright CL: Guidelines for reporting experiments involving animals: the ARRIVE guidelines. Br J Pharmacol 2010;160:1573-1576.

$>17$ Belayev L, Alonso OF, Busto R, Zhao W, Ginsberg MD: Middle cerebral artery occlusion in the rat by intraluminal suture. Neurological and pathological evaluation of an improved model. Stroke 1996;27:16161622.

18 Sutherland BA, Buchan AM: Alteplase treatment does not increase brain injury after mechanical middle cerebral artery occlusion in the rat. J Cereb Blood Flow Metab 2013;33: e1-e7.

19 Garcia JH, Wagner S, Liu KF, Hu XJ: Neurological deficit and extent of neuronal necrosis attributable to middle cerebral artery occlusion in rats. Statistical validation. Stroke 1995;26:627-634.

20 Ikeda-Matsuo Y, Ota A, Fukada T, Uematsu S, Akira S, Sasaki Y: Microsomal prostaglandin E synthase-1 is a critical factor of stroke-reperfusion injury. Proc Natl Acad Sci U S A 2006;103:11790-11795. 


\section{Cellular Physiology Cell Physiol Biochem 2017;43:1273-1287

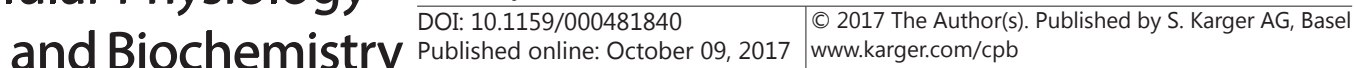

-21 Wang J, Jiang C, Liu C, Li X, Chen N, Hao Y: Neuroprotective effects of progesterone following stroke in aged rats. Behav Brain Res 2010;209:119-122.

22 Ashwal S, Tone B, Tian HR, Cole DJ, Pearce WJ: Core and penumbral nitric oxide synthase activity during cerebral ischemia and reperfusion. Stroke 1998;29:1037-1046.

23 Yu Z, Zhou D, Bruce-Keller AJ, Kindy MS, Mattson MP: Lack of the p50 subunit of nuclear factor-kappaB increases the vulnerability of hippocampal neurons to excitotoxic injury. J Neurosci 1999;19:8856-8865.

-24 Zhu H, Zhang Y, Shi Z, Lu D, Li T, Ding Y, Ruan Y, Xu A: The Neuroprotection of Liraglutide Against Ischaemiainduced Apoptosis through the Activation of the PI3K/AKT and MAPK Pathways. Sci Rep 2016;6: 26859.

-25 Kim HS, Whang SY, Woo MS, Park JS, Kim WK, Han IO: Sodium butyrate suppresses interferon-gamma-, but not lipopolysaccharide-mediated induction of nitric oxide and tumor necrosis factor-alpha in microglia. J Neuroimmunol 2004;151:85-93.

26 Thrift AG, Thayabaranathan T, Howard G, Howard VJ, Rothwell PM, Feigin VL, Norrving B, Donnan GA, Cadilhac DA: Global stroke statistics. Int J Stroke 2017;12:13-32.

27 Biewenga GP, Haenen GR, Bast A: The pharmacology of the antioxidant lipoic acid. Gen Pharmacol 1997;29:315-331.

-28 Panigrahi M, Sadguna Y, Shivakumar BR, Kolluri SV, Roy S, Packer L, Ravindranath V: alpha-Lipoic acid protects against reperfusion injury following cerebral ischemia in rats. Brain Res 1996;717:184-188.

29 Packer L, Tritschler HJ, Wessel K: Neuroprotection by the metabolic antioxidant alpha-lipoic acid. Free Radic Biol Med 1997;22:359-378.

30 Clark WM, Rinker LG, Lessov NS, Lowery SL, Cipolla MJ: Efficacy of antioxidant therapies in transient focal ischemia in mice. Stroke 2001;32:1000-1004.

-31 Connell BJ, Saleh M, Khan BV, Saleh TM: Lipoic acid protects against reperfusion injury in the early stages of cerebral ischemia. Brain Res 2011;1375: 128-136.

-32 Ding Y, Chen M, Wang M, Li Y, Wen A: Posttreatment with 11-Keto-beta-Boswellic Acid Ameliorates Cerebral Ischemia-Reperfusion Injury: Nrf2/HO-1 Pathway as a Potential Mechanism. Mol Neurobiol 2015;52:1430-1439.

33 Li L, Zhu K, Liu Y, Wu X, Wu J, Zhao Y, Zhao J: Targeting thioredoxin-1 with siRNA exacerbates oxidative stress injury after cerebral ischemia/reperfusion in rats. Neuroscience 2015;284:815-823.

34 Janero DR: Malondialdehyde and thiobarbituric acid-reactivity as diagnostic indices of lipid peroxidation and peroxidative tissue injury. Free Radic Biol Med 1990;9:515-540.

35 Shi C, Zhou X, Zhang J, Wang J, Xie H, Wu Z: $\alpha$-Lipoic acid protects against the cytotoxicity and oxidative stress induced by cadmium in HepG2 cells through regeneration of glutathione by glutathione reductase via Nrf2/ARE signaling pathway. Environ Toxicol Pharmacol 2016;45:274-81.

-36 Wu MH, Huang CC, Chio CC, Tsai KJ, Chang CP, Lin NK, Lin MT: Inhibition of Peripheral TNF- $\alpha$ and Downregulation of Microglial Activation by Alpha-Lipoic Acid and Etanercept Protect Rat Brain Against Ischemic Stroke. Mol Neurobiol 2016;53:4961-4971.

-37 Zhong ZY, Tang Y. Upregulation of Periostin Prevents High Glucose-Induced Mitochondrial Apoptosis in Human Umbilical Vein Endothelial Cells via Activation of Nrf2/HO-1 Signaling. Cell Physiol Biochem. 2016;39:71-80.

-38 Kobayashi A, Kang MI, Okawa H, Ohtsuji M, Zenke Y, Chiba T, Igarashi K, Yamamoto M: Oxidative stress sensor Keap1 functions as an adaptor for Cul3-based E3 ligase to regulate proteasomal degradation of Nrf2 Mol Cell Biol 2004;24:7130-7139.

-39 Wakabayashi N, Dinkova-Kostova AT, Holtzclaw WD, Kang MI, Kobayashi A, Yamamoto M, Kensler TW, Talalay P: Protection against electrophile and oxidant stress by induction of the phase 2 response: fate of cysteines of the Keap1 sensor modified by inducers. Proc Natl Acad Sci U S A 2004;101:2040-2045.

40 Ryter SW, Alam J, Choi AM: Heme oxygenase-1/carbon monoxide: from basic science to therapeutic applications. Physiol Rev 2006;86:583-650.

41 Valdecantos MP, Prieto-Hontoria PL, Pardo V, Módol T, Santamaría B, Weber M, Herrero L, Serra D, Muntané J, Cuadrado A, Moreno-Aliaga MJ, Alfredo Martínez J, Valverde ÁM: Essential role of Nrf2 in the protective effect of lipoic acid against lipoapoptosis in hepatocytes. Free Radic Biol Med 2015;84:263-278.

$>42$ Xu Z, Croslan DR, Harris AE, Ford GD, Ford BD: Extended therapeutic window and functional recovery after intraarterial administration of neuregulin-1 after focal ischemic stroke. J Cereb Blood Flow Metab 2006;26:527-535. 